Pecvnia, 5 (2007), pp. 53-86

\title{
Moneda y crédito en el Reino de León (1000-1500)
}

\author{
Eduardo Fuentes Ganzo
}

eduardo.fuentes@unileon.es Universidad de León

Dpto. de Dirección y Economía de la Empresa Fac. de Ciencias Económicas y Empresariales Campus de Vegazana, s/n 24071 León (España)

\begin{abstract}
A León Hernández-Canut y Fernández-España (1955-2008).
Erudito, numismata, abogado y amigo. In Memoriam.
\end{abstract}

La historia económica medieval del Reino de León se refleja muy bien a través de la evolución de las formas de pago y más concretamente a través de la moneda que se acuño y circuló, tanto autóctona como foránea. La composición de sus metales y su uso proporcionan datos concluyentes acerca de la evolución económica del territorio. En este artículo se realiza un análisis en perspectiva del dilatado periodo pleno y bajo medieval.

Palabras clave: Historia monetaria, Reino de León, moneda medieval, bimetalismo, quiebra de moneda, moneda forera, ceca, circulación monetaria, Ferias.
The Economic history of medieval Kingdom of Leon is reflected through the evolution of payment practices, and further, through the coinage. The metallic composition of coins and their uses bring us fundamental information about the territorial economic development. In this article we make a wide economical analysis of the late medieval times.

Key words: Monetary History, Leon Kingdom, medieval coinage, bimetalism, coin's adulteration, monetary tax in Parliament, mint factory, monetary circulation, "Ferias". 


\section{LOS PRECEDENTES}

En el periodo histórico convencionalmente acotado como Alta Edad Media entre los siglos V y IX, tras el cataclismo del mundo romano, se produjo en Occidente una contracción del intercambio económico y una regresión a prácticas económicas autárquicas y escasamente monetizadas. Únicamente en el periodo visigodo entre los siglos VI y VIII se batió numerario en pequeña cantidad y casi siempre por motivos de prestigio en una rudimentaria acuñación áurea: los tremises, una burda y estereotipada imitación en peso y tipo de los áureos imperiales romanos.

La contracción de la actividad económica y el aislamiento, condujo a una economía casi exclusivamente de trueque en los nacientes estados cristianos no ocupados por el emirato cordobés a partir del siglo VIII (Pirenne 1980); por lo que se siguió utilizando la moneda bajo imperial romana. La pervivencia en el uso del numerario romano se constata en los testimonios documentales coetáneos, como en el libro Becerro de Sahagún, en el que se documentan operaciones como la del año 877 al referirse a la compra de dos bueyes con su carro y arreos, valorándose en "15 sueldos romanos" (Sánchez-Albornoz 1965: 35).

Ejemplos de esta realidad y modo de operar en los intercambios en el reino astur leonés que emerge en el siglo VIII lo reflejan alguno de los diplomas que han llegado hasta nosotros, como en un documento al que se refirió, en su día, el propio Sánchez Albornoz datado en el año 861, en que la operación económica se perfecciona a través de una permuta en la que una tal Daide y su marido intercambian una viña en Piasca a cambio de un buey negro: "buoe colore nigrum" (Sánchez Albornoz 1944: 341). En el mismo sentido, en la colección diplomática del monasterio de San Vicente de Oviedo, se cita el intercambio realizado en el año 877 entre un tal Severiano que en la localidad asturiana de Llanera permuta al diácono Indisclo unas propiedades a cambio de un buey, una vaca, dos ovejas, telas, prendas de vestir y dos modios de trigo (Floriano Llorente 1968).

\section{LAS PRIMERAS AMONEDACIONES LEONESAS (ca. 1070)}

En el siglo $X$, en el espacio occidental de la península, del viejo tronco del reino leonés se emancipa Castilla como condado independiente, primero, y como reino después; en ambos reinos se darían a 
lo largo de los siglos $\mathrm{X}$ y $\mathrm{XI}$ las mismas y muy contraídas prácticas monetarias y comerciales hasta que nuevamente son sucesivamente unificados por Sancho el Mayor y Alfonso VI. Será justamente en este segundo periodo de unión de reinos cuando, tras la toma de Toledo en el 1085, comiencen las acuñaciones autóctonas, momento singularmente relevante, ya que se puede establecer esa fecha al llegar los reinos cristianos la línea del Tajo, como el momento en que se invierten las preponderancias peninsulares. Este hecho de prestigio requirió por parte de Alfonso $\mathrm{VI}$, una sanción ideológico-simbólica y económica a un tiempo: acuñar moneda. Esa acuñación se realizará en tres cecas o casas de moneda, a saber, una en el nuevo espacio conquistado -Toledo- y dos en talleres del viejo reino leonés: León (como casa de moneda real) y Santiago de Compostela como ceca concesionaria cedida por la Corona al todopoderoso arzobispo.

Figura 1: Obolo de Vellón (divisor del dinero) acuñado por Alfonso VI en León ca. 1080
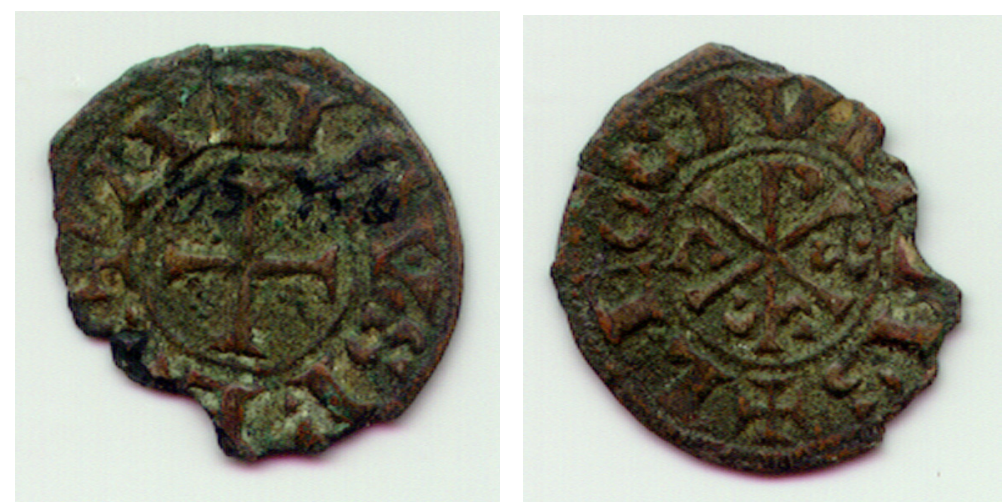

Cortesía del Museo de León, Junta de Castilla y León, nº inv. 2454.

Hasta esos años de finales del siglo XI, no sólo el Reino de León, sino los restantes estados cristianos se ha utilizado para las escasas transacciones un doble patrón bimetálico (de oro y plata) inspirado en los sistemas foráneos más avanzados; por un lado existen circulando desde el siglo VIII monedas acuñadas por los emires omeyas independientes con ceca del Al Andalus, y desde el siglo X, con Abderramán III, monedas califales andalusíes a las que sucederán los sistemas almorávides y almohades, que eran los vigentes al inicio de las acuñaciones cristianas.

Todos estos sistemas monetarios se fundamentaban en un doble patrón: oro y plata, oro, a través del Dinar, y plata a través del 
Dihrem, en lo que han dado en llamarse sistemas bimetálicos (como antaño lo fue el romano) que exigían una relación estable de cambio o equivalencia entre ambos metales.

Figura 2: Dinar Ceca Murcia, 554 hégira
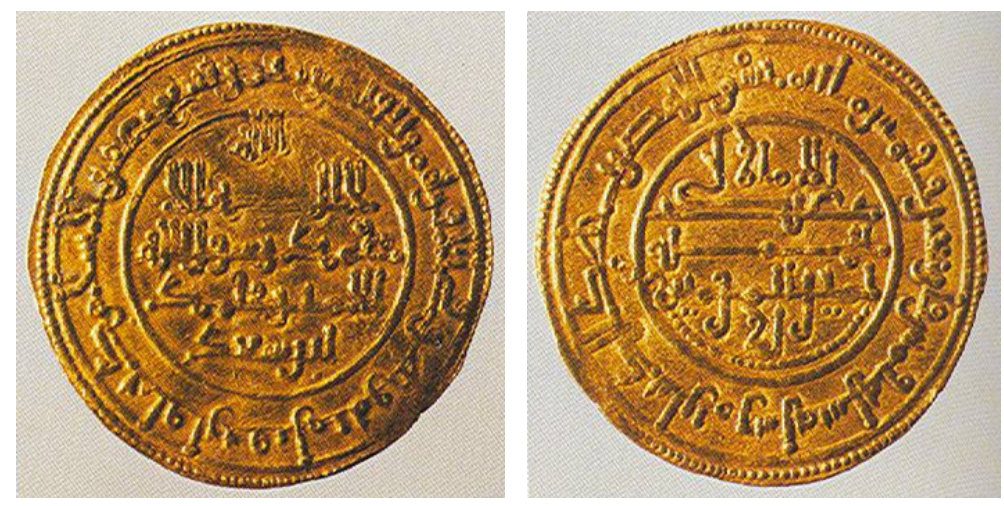

Museo Arqueológico Nacional nº 104157.

Aunque el oro circulaba abundantemente en León y Castilla, al menos desde el siglo IX, como acreditan las abundantes menciones a mancusos, mencales o Mizcales "ex auro purisimo" (Sánchez-Albornoz 1928 y Rueda Savater 1991), y como nosotros mismos hemos acreditado (Fuentes Ganzo 1998 y 2003), no será hasta el último tercio del siglo XI cuando se acuñe en León y Castilla. El valor estratégico y simbólico que tuvo la recuperación de la vieja sede goda, comportó, además, la consolidación de la línea del Tajo, lo que supuso fundamentales ventajas económicas, ya que el oro comenzó a afluir en abundancia al reino como resultado de las abundantes parias y tributos de guerra, de forma que el entonces reino de León y Castilla se convierte en el primero de la cristiandad que comienza a acumular excedentes de oro de procedencia subahariana. Por ello la necesidad de prestigio, la disponibilidad del metal y por la probable preexistencia en Toledo -ahora bajo control cristiano- de una ceca andalusí, dotada de hábiles artesanos y maestros monederos, conducirían al inicio del ciclo acuñador; de hecho las monedas de Alfonso $\mathrm{VI}$, son técnicamente más perfectas en cuanto a la calidad del grabado que las de sus sucesores. Con ello se inicia la acuñación del oro, además de acuñaciones de dineros de vellón, haciendo del territorio el primer estado cristiano que reintroduce el oro en la moneda y adelantándose en más de un siglo al resto de los Reinos occidentales de Europa. 
3. LA CIRCULACIÓN MONETARIA EN EL REINO: Siglos XII-XIII

\section{A. Del bimetalismo formal al trimetalismo}

Alfonso VIII va a hacer acuñar en Toledo con una cruz y caracteres islámicos los primeros morabitinos o maravedís de oro cristianos siguiendo el sistema musulmán, no solo en tipo (salvo la discreta inclusión de una cruz al principio de la leyenda).

Por otro lado, como el oro quedaba reservado para los grandes pagos y para tesaurizarse, se planteaba la necesidad de crear un numerario de más escaso valor y susceptible de acuñarse sin excesivos costes para las transacciones corrientes del pueblo, y al igual que para el oro se tomó como base el sistema monetario islámico de piezas que más circulaban en los territorios de León y Castilla, para el más pequeño numerario, teóricamente de plata se tomó un segundo modelo, el de los dineros ultrapirinaicos conforme al sistema carolingio que también circulaban en el reino, con un peso teórico de $1,5 \mathrm{grs}$. de plata, ya que la talla partía del marco ( 230 grs.) se dividía en 8 sueldos que habrían de contener 12 dineros cada uno; pero, una vez más, la necesidad igual que estaba pasando allende los Pirineos, excedía a la teoría, y la necesidad de labra un numerario abundante, hizo para el patrón plata que el teórico sistema bimetálico oro-plata de doble filiación (islámica para el oro y franca para la plata) que se establece en Castilla desde el 1085, fuese en realidad un sistema oro-vellón, naciendo corrompido respecto a la divisa de plata, ya que los dineros se labrarán en vellón, una liga pobre de plata con cobre que en aquéllas primeras acuñaciones tendría en torno al $30 \%$ de plata (Rueda 1991). Aunque el oro no se acuñó en reinados sucesivos hasta casi un siglo después, en un nuevo momento de separación de reinos, con los reinados de Fernando II (en León) y Alfonso VIII (en Castilla), que acuñan sus respectivos maravedís en un nuevo impulso reconquistador con el consiguiente flujo de oro, siempre estará presente en el sistema monetario por la monedas de procedencia andalusí primero y tras la difusión de la moneda de oro en occidente por las transacciones con otros países.

El oro amonedado evolucionará definitivamente en el territorio con Fernando III, hacia 1250, en que aprovechando la transitoria liquidez tras la toma de Sevilla, sustituirá los maravedís con raíz e identificación ponderal con el dinar almoraví, por la Dobla o doble dinar almohade, de doble peso y por tanto divisa más consistente, término que hará fortuna en Castilla como divisa de oro. 
La plata, por su parte, siempre generó problemas de aprovisionamiento en Castilla, a diferencia del resto de Europa donde se estableció con efectividad un sistema bimetálico plata-vellón, ya que se daba una mayor abundancia de plata, puesto que si bien el oro afluía a Castilla regular y considerablemente, la misma situación se da para la Europa transpirenaica respecto a la plata desde el tempranos momento de finales del siglo XII se producen aportes regulares y considerables de plata, redescubriendo minas y vetas de plata en Freiberg en Sajonia hacia 1170 ó en Mantieri, Toscana, hacia 1190, incluso cabe afirmar que en el dilatado periodo entre 1160 y 1310, en la zonas de Estiría o en los Alpes occidentales, hubo pocas décadas en que no se incrementara la producción de plata (Riera Melis 2000).

Por tanto, se dio la paradoja inversa, del mismo modo que el sistema monetario del resto de la Europa Cristiana se vio condicionado por la carencia de oro, los sistemas hispánicos y particularmente el castellano se vio condicionado por la carencia del metal argénteo.

Por ello, no extraña que en León y Castilla, bajo la misma Corona, no se acuñe en plata de buena ley hasta de un modo restringido por Alfonso X, en la segunda mitad del XIII, siendo este un hecho episódico, relacionado con conductas, de un rey que sistemáticamente quebró y menoscabó la moneda, por razones de prestigio y de "fecho imperio"; de hecho en la sedición de Sancho IV con las hermandades de 1282, una de las exigencias de los concejos es que se restaure la buena moneda de los tiempos de su padre (Hernández-Canut 1998). Y no será hasta mediados del siglo XIV cuando con Pedro I, haga aparición una divisa fuerte de plata en Castilla, el real. Es en ese momento cuando ya podemos hablar de un cierto "trimetalismo" o de un sistema trimetálico: Oro-plata-vellón (oro con la dobla, plata con el real y sus fracciones, y vellón para el resto de la moneda menuda de amplia circulación, cornados y dineros novenes). El sistema se perpetuará durante el bajo medievo, lo que contrasta con la amplia acuñación en plata en el resto de los estados transpirenaicos e incluso peninsulares como Venecia, Francia o Cataluña, que desde los siglos XII y XIII van acuñando más o menos regularmente plata, los cruzados tuvieron bastante que ver en los espacios portuarios italianos, por ejemplo para la cuarta cruzada en a comienzos del XIII alquilan a Venecia embarcaciones para Palestina por valor de 85.000 marcos de plata, eso daba para muchos años de acuñación de los gross venecianos de tanta difusión en Europa, poco después en 1222 comenzará Génova, en 1237 
Florencia, Ramón Berenguer de Cataluña para Provenza en 1245 ó San Luis de Francia en 1266, en cualquier caso un siglo antes que en Castilla.

El sistema monetario de Castilla, en definitiva, invirtió los patrones europeos, tardíamente para la plata y como pionera en la cristiandad para el oro, ya que el metal amarillo se acuñó aquí más o menos regularmente desde el año 1087, por la afluencia del oro saubsahariano a través de las parias y tributos, habiendo de esperar occidente casi dos siglos, en el año 1246 en Lucca o en Génova y Florencia en 1252, donde aparecerá el florín, llamado a convertirse la gran divisa de oro del bajomedievo en Europa.

Indudablemente la vigencia del bimetalismo, temprana en León, creaba un sistema monetario mucho más complejo que exigía de una relación estable entre el oro y la plata, pero también generaba tensiones, ya que cada cierto tiempo por las fluctuaciones de la oferta y la demanda de ambos metales había de revisarse, esas tensiones no siempre se resolvían y leemos continuamente disposiciones de Cortes en Castilla tasando el valor en cambio de todas las divisas de oro (M. Colmeiro Cortes de lo Antiguos reinos, por ejemplo las Cortes de Toro de 1373), crisis que, en muchas ocasiones, se cerraban en falso mediante el recurso de la quiebra de moneda, la mutatio moneta a la que nos referiremos.

3B. El imperio del vellón. La alquimia de fingir plata. Las

cecas

No existe apenas documentación sobre las técnicas de acuñación de moneda en la Edad Media hispánica, por lo que en gran medida hay que conjeturar cómo se fabricaría la moneda y cuáles serían las cecas o casas de acuñación; para Castilla existen, no obstante, dos fuentes documentales de primera magnitud: en primer lugar una iconográfica, la arquivolta del pórtico de la Iglesia de Santiago en Carrión, que contiene una acabada representación iconográfica de diversos artesanos en un proceso de fabricación de moneda, la fábrica de la iglesia es de la segunda mitad del siglo XII, entonces Carrión es territorio de realengo en una zona disputada por León y Castilla, y enclave en que por la época se realizan prestigiosas curias en tiempos del castellano Alfonso VIII y su leones primo Alfonso IX, relieves, que recientemente han sido objeto de estudio por Julio Torres (2000). En segundo lugar conocemos muy recientemente un interesante manuscrito que ha sido recientemente exhumado y publicado (Caunedo y Córdoba 2000) se conserva en el 
Archivo de la Real Colegiata de San Isidoro de León (manuscrito 46); se trata de un texto que se data a finales del siglo XIV, 1393 y que tiene un doble contenido en primer lugar un tratado de aritmética y en segundo lugar otro "Libro que enseña a ensayar cualquier moneda", por lo que sería, este texto leonés el más antiguo tratado de arte de ensayo de moneda que se conserva en la península, prácticamente coetáneo al manuscrito o manual de mercadería del manuscrito 4 de la Biblioteca Universitaria de Barcelona, considerado como el primer manual hispánico de mercadería (Gual 1981). Ambos corresponden a una época en que la aritmética comercial y el arte de mercadear se vinculaban de modo inextricable a los pesos de las monedas, la determinación de la finura de los metales y el arte de ensayar moneda; sin embargo el manuscrito leonés aventaja al catalán en la descripción de las técnicas de ensayar y fabricar moneda, ya que se concibe para uso de ensayadores y maestros de las casa de moneda, en tanto que el segundo se concebía más como un manual de uso de mercaderes.

Además de los preciosos datos que proporcionan las dos fuentes antes referidas, si se pueden extrapolar datos de técnicas de fabricación por cotejo con documentación coetánea de la vecina Francia, mucho más documentada por la abundancia de más titulares del "ius moneta", además del rey, dada la profusa trama de moneda feudal, y por ende de más talleres de moneda, con la mayor producción documental que comportaba, cuando aquí la moneda era directamente real o concesionaria; por ejemplo Marc Bompaire, cita un documento de 1128, en que se establece un derecho de monedaje a favor delos maestros de una casa de moneda en doce dineros por libra, es decir en torno a un $5 \%$ de la labor acuñada (Bompaire 2000); nada en cambio se especifica para momentos tan tempranos en las casi coetáneas concesiones de moneda en los leoneses espacios de Lugo o Santiago, o en la palentina ceca de San Antolín.

En los espacios leoneses, en la práctica, sólo se dieron dos formas de organizar la acuñación de moneda, que siempre fue regalía exclusiva de la Corona, o bien por concesión de la ceca a favor de una autoridad primero episcopal o abacial, en los momentos más pretéritos, o luego, más tardía y episodicamente a favor de señores laicos -como en las concesiones de Enrique IV-, o bien por arrendamiento, por el que la corona enajenaba temporalmente la facultad de batir moneda a favor de un particular; pero en cualquier caso siempre se acuñaba en nombre del rey y bajo su autoridad. 
Figura 3: Manuscrito 46 de la R. Colegiata de San Isidoro de León donde se contiene "El arte de ensayar moneda" de 1393. Copia S. XVI.
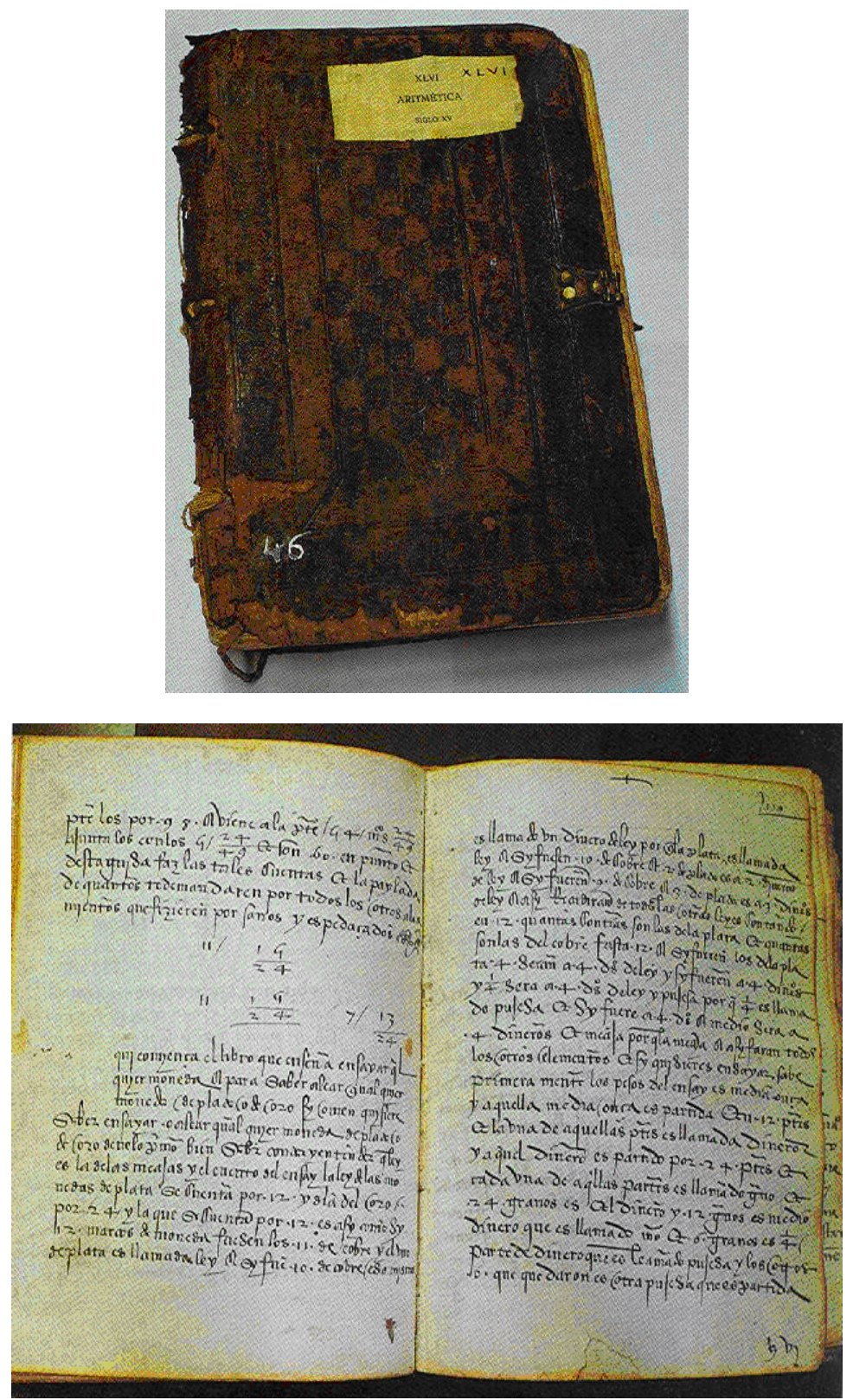

Fotografía Claudio de la Cal.

Sea cual fuere la forma de explotación de la Casa de moneda o ceca, el procedimiento sería el siguiente: El maestro encargado de la acuñación se aprovisionaba de los metales necesarios, fundamentalmente 
de plata y cobre -la acuñación del oro estaba más restringida, por ejemplo durante los reinados de Fernando II y Alfonso IX tan solo se batía oro por concesión al obispo en la ceca de Salamanca-. En primer lugar calculaba matemáticamente las proporciones que había de emplear de cada metal para obtener la aleación de vellón con la ley exigida, la finura del vellón se determinaba por ley duodecimal estimada en dineros, una ley de 12 dineros, sería plata pura, en tanto que una ley de 3 dineros $(1 / 4$ parte de plata) obligaría a una aleación de un $75 \%$ de cobre y un $25 \%$ de plata, a su vez par afinar más los dineros se dividían en meajas, pujesas y granos, de forma que cada dinero contenía 2 meajas ó 4 pujesas ó 24 granos, es decir se podía afinar hasta 288 granos, y dicho de otra forma una ley de 4 dineros y pujesa equivaldría a lo mismo que decir 4 dineros y 6 granos. Para el oro se hacía una división más afinada en 24 quilates. El manuscrito leonés plantea con afán didáctico problemas prácticos:

Y si te dixere que el rey manda lavrar moneda de ley de once dineros e seis gramos e tenemos aquí pla(ta) de dos guisas, la una es a ley de 11 dineros e 15 granos (casi plata pura) e la otra es a ley de 7 dineros e 13 granos (plata de unas 625 milesimas) ¿qué plata tomaremos de cada una destas...

Respecto al vellón había cierto margen y se permitían desvíos de más menos un grano, no así para el oro, cuyo control era más riguroso.

Una vez determinadas las proporciones de metal, tras los cálculos del maestro de moneda, los metales se fundían en el horno de fundición en la cantidad determinada por este, obteniéndose los lingotes de metal, sobre los que el maestro ensayador verificaba un primer ensayo, para comprobar que la aleación se ajustaba efectivamente a la ley y finura exigidas; el ensayo se hacía por un sistema de copelación, que era una base o copa confeccionada con hueso y recubierta de ceniza para evitar que el resultado del ensayo se adhiriera a sus paredes, dentro de un hornillo. El sistema para precipitar consistía en dejar que se oxidase el cobre que contenía a altas temperaturas reaccionando con plomo que se añadía, de forma que al final quedase la plata pura, ésta, tras el ensayo se pesaba nuevamente y daba la ley, por ejemplo si la ley era de cuatro dineros y se había introducido el peso de 12, al final en plata pura tenía que haber el peso de cuatro. El proceso requería de una gran precisión y pericia técnica, no se podía añadir plomo de más pues al final no se fundiría todo y arruinaría la muestra, o un exceso de temperatura o un calentamiento demasiado brusco de la copela podía reventarla, o incluso 
quedar burbujas del gas oxidado en el resultado del ensayo por insuficiencia de plomo (Caunedo y Córdoba 2000).

Julio Torres tiene tipificados a diez de los 24 personajes de la arquivolta de la Iglesia de Santiago de Carrión, que supone relacionados con la labor monetal, identificando a ocho de los artesanos del relieve con una sabia mezcla de competencia e imaginación: Un obrero aplanando rieles, un recocedor, un cortador de cospeles, un acuñador, un redondeador de cospeles, un blanqueador, un soplador de fragua y un escribano (Torres 2000).

Pero sigamos con el proceso, tras ello, los lingotes se fundían y se hacían delgadas láminas de metal en torno a un milímetro, que se pesaban y entregaban a los operarios para su corte, recortando los cospeles sobre los que se acuñaría, parece que en el siglo XII, esto se haría a tijera, tras el corte estos entregaban los cospeles, y los restos de las láminas que se volvían a pesar para evitar sustracciones. Los cospeles pasaban luego a los talladores que acuñarían las monedas troquelando lo negativos a golpe de martillo, primero de anverso y luego de reverso, previamente para que las piezas tuvieran más ductilidad habían de ser recalentadas en una especie de sartenes por los recocedores (Torres 2000).

Tras la acuñación venía el blanqueado que se haría mediante un proceso químico que eliminaría el cobre superficial, para dar una aspecto más argénteo a las monedas, sumergiendo durante algunos segundos las mismas en una mezcla de salitre y agua, provocando con el ácido natural una nueva oxidación del cobre (Caunedo y Córdoba 2000). Se practicaba, además un ensayo final sobre un muestra de las monedas ya blanqueadas para certificar nuevamente la ley, a pesar de los controles intermedios de guardias y pesajes, la muestra del ensayo junto con el acta las custodiaría el maestro de la ceca, tras ello se haría la entrega de la moneda acuñada a los oficiales del rey, probablemente a algunas de las funciones de levantamientos de actas corresponde el escribano de la arquivolta, al que no nos debe sorprender su hábito de monje porque muchas cecas, sobre todo del XII eran concesiones a obispos o abades.

En las monedas se improntaban, además de las características de la emisión figuras y leyendas que la ordenanza de moneda determinase, la marca de la ceca, "B" de Burgos, "L" de León, "T" de Toledo, "S" de Sevilla, las cuatro, acaso más difundidas en los tiempos medievales, pero en ocasiones estas marcas eran signos parlantes, por ejemplo, una venera para Coruña o Santiago, o una especie de copa o cuenco para Cuenca, e 
incluso otros signos que evidentemente responden a la ceca pero que aún no han podido determinarse con precisión como una muy frecuente ceca de tres puntos en muchos dineros de Fernando IV.

Los maestros ensayadores también podían poner sus marcas, pero aún teniendo casi la certeza de que muchas de estas marcas auxiliares responden a la identificación del ensayo, que incluso se repiten en cecas distintas, por un probable desplazamiento o itinerancia del maestro ensayador, aún no se sabe mucho de ellas salvo las aportaciones de Josep Pellicer, más para los tiempos medievales por análisis tipológicos que documentados (Pellicer 1997) por ejemplo para Cuenca determina la presencia documentada de un ensayador Diego Alvarez en torno a 1475 y también una marca de ensaye de dos estrellas. En Burgos una marca de ensaye de un círculo, que efectivamente se localiza según tenemos comprobado en moneda burgalesa en tiempos desde Alfonso XI a Enrique II, pero también hemos hallado aspas en Burgos y círculos en León, en Coruña dos glóbulos (piénsese en los dineros novenes de Enrique II), en Segovia tres puntos dispuestos en triángulo, pero que para tiempos de Enrique IV también tenemos localizado en cecas manchegas.

La evolución de las casas de moneda medievales desde las primeras acuñaciones de Alfonso VI (siglo XII) en León, Santiago y Toledo ( 2 enclaves leoneses y uno castellano) a las de Enrique IV (siglo XV) con casi un centenar de casas de moneda, y en torno a una veintena en los siglo XII y XIV.

\section{Falsificadores "Reales"}

3C. "Mutatio moneta" (la quiebra de la moneda):

Por no remontarnos a unidades de peso y valor mucho más pretéritas y abstrusas, digamos que la unidad de medida en peso en Castilla para la plata, al menos desde el siglo XIII era el Marco de Burgos o de Colonia, y para el oro, lo era el de Toledo, ambos pesaban 230 gramos (Ladero 2000). En principio y por definición la propia moneda era una mercancía, de forma que su valor en cambio había de ajustarse a su peso, es decir su valor era real, o dicho de otra forma, en teoría un dinero de plata del que se predicaba un valor nominal contenía en peso exactamente la cantidad de plata por ese valor, de forma, que como pago, igual daría una cantidad de plata en barra sin acuñar que la misma en moneda acuñada. Esto que parece un despropósito en el mundo contemporáneo, donde el dinero tiene un valor fiduciario, donde el papel 
en que se acuña apenas tiene valor intrínseco, en el medievo, y aún hasta tiempos relativamente recientes, nadie lo dudaba, no porque tuviera ese valor sino porque había convertibilidad en metal precioso de ese valor que el poder político y la autoridad monetaria respaldaban, de hecho todavía leemos "El Banco de España pagará al portador...", y esto, en el mundo medieval era un axioma.

Sin embargo, la realidad, era una realidad de escasez general, y de escasez de metal precioso, especialmente en el caso de la plata para León y Castilla federadas; en consecuencia no había suficiente metal para atender a las actividades económicas en una economía cada vez más monetizada, de forma que la gran parte de la masa monetaria, la que de verdad circulaba se acuñaba en vellón, una mezcla pobre de plata y cobre, a la que, como vimos, se procuraba dar el aspecto más argénteo posible; el resultado fue que apareció de hecho, en el sistema, como moneda más circulante que tenía un valor nominal superior al de la plata que contenía, teóricamente, como vimos, en definitiva como una moneda fiduciaria. El dinero carolingio que inspiraba las acuñaciones de plata debía de pesar un gramo y medio de plata, cuando en realidad los primeros dineros de Alfonso $\mathrm{VI}$, no pesaban más allá del gramo, y además sólo contenían un $33 \%$ de plata en los mejores casos, y desde ahí toda la evolución del vellón en la moneda castellana, es una continua reducción de las ligas de plata que han hecho afirmar a algún estudioso que "el sistema. Castellano se caracterizó siempre por una falta de estabilidad crónica" (Mackay 1980).

En principio y a pesar de la posibilidad de manipular la moneda que el "ius moneta" ofrecía a su titular, el monarca, parece que no hubo grandes tentativas de alterar la moneda, pero muy pronto sin haber transcurrido un siglo desde la reintroducción de un sistema monetario autóctono surgió la primera crisis aguda, que se va a dar en el momento de separación de los Reinos y especialmente en el espacio leonés con Fernando II, que se encuentra como titular de un reino estrangulado territorialmente entre Castilla, a su oriente, y Portugal, nacido como reino en la época de su padre Alfonso VII el "emperador" a su occidente, pero además también estrangulado económicamente, con un territorio muy señorializado con poderosos señores de mitra que dejaban escasas oportunidades recaudatorias a la corona, las posibilidades de obtener recursos económicos por la vía de la emisión de moneda no pasó desapercibida ni al propio Fernando II ni a su sucesor Alfonso IX que vio la posibilidad de estirar el dinero acuñado recortando la ley de la moneda, 
expresado más claramente, poniendo más cobre y menos plata en cada unidad; esto va a producir la primera gran devaluación de la moneda medieval que conocemos a finales del siglo XII entre 1196 y 1197, tras la guerra con Castilla (Fuentes Ganzo 2000a). El maravedí que vimos como divisa de Oro, además servía para contar el dinero corriente y dar valor a los objetos, es decir los precios y la propia moneda se podían contar en maravedís, teóricamente el maravedí leones, "maravedí lungo" era más fuerte que el castellano con una ley de 11 dineros menos $1 / 3$, frente al castellano "maravedí curto" de 10 dineros y medio, este maravedí valdría 8 sueldos de doce dineros cada uno, según el sistema universal en Europa de 12 dineros por sueldo. Pues bien, asistimos, desde el siglo XII, a una progresiva devaluación del dinero, de forma que a principios de siglo el maravedí kacimí o islámico valía 4 sueldos, es decir 48 dineros (año 1117, Anales toledanos) sin embargo cuando en 1179 lo acuñan Fernando II en León y Alfonso VIII en Castilla valía 6 sueldos es decir 72 dineros (tal como se refleja en los Fueros de Uclés y Cuenca) y en el año 1192 valdría 84 dineros el maravedí leonés y 90 el castellano, era algo más fuerte el leonés -no olvidemos que era el tiempo en que Alfonso VIII aún estaba sometido a la tutoría de su tío el rey leonés-; es decir había que dar menos dineros de vellón por cada maravedí de oro, que a su vez era una unidad de cuenta, si algo valía por ejemplo 3 maravedís castellanos, se quería decir que su precio era de $\mathbf{2 7 0}$ dineros.

Figura 4: Anversos del maravedí de oro de Alfonso IX de León
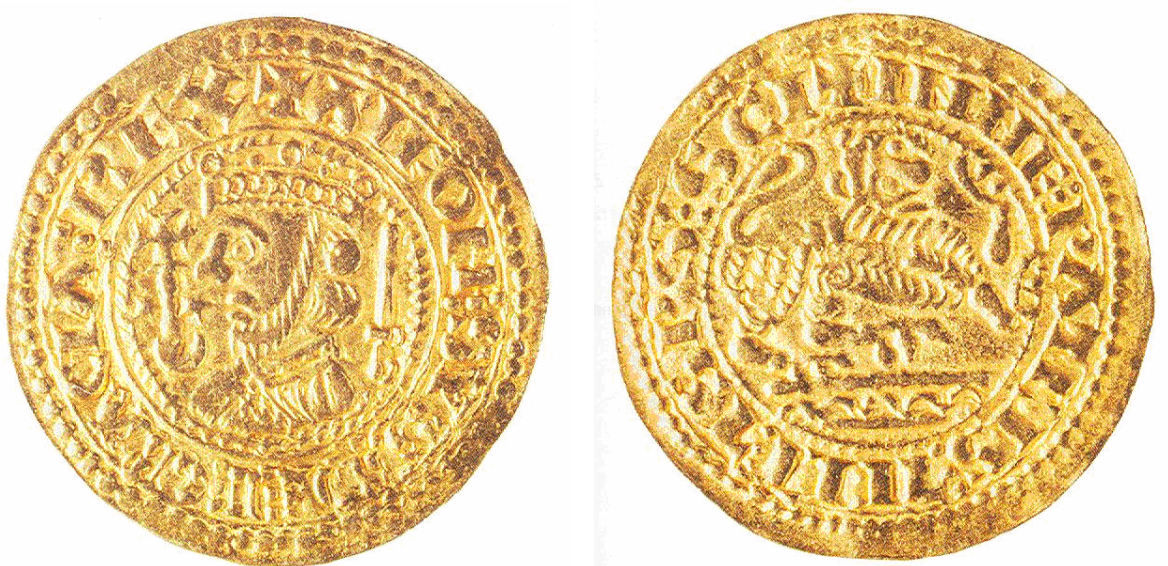

Fotografía cortesía del MAN, no inventario 1973/24/17005. 
Tras la guerra con Castilla, ya en tiempos de Alfonso IX, en 1197, la escasez de recursos del erario leonés hace que se envilezcan sus dineros y el dinero leonés en los documentos pasa a valer menos que el castellano, que hará que en 1202 -Cortes leonesas de Benavente- el pueblo exija y obtenga el compromiso del rey de no alterar la moneda por siete años a cambio de un impuesto un maravedí por persona -algo más de 90 dineros-. De hecho el maravedí de cuenta en 1217 (según se refleja en el Tratado de Toro) era equivalente 96 dineros leoneses y tan solo 90 burgaleses).

Al final de modo solemne se termina diciendo que el rey vendió la moneda a las gentes de la tierra por siete años, pagando estas un maravedí por persona y año.

Es curioso constatar como en el territorio menos feudal de la Europa de entonces en lo monetario, donde la moneda es del rey y solo del rey, cuando a tenor de las doctrinas tomistas y de la primera glosa nadie se planteó nada parecido y habría que esperar a mediados del XIV, para que Oresme, lo comience a plantear doctrinalmente desde espacios navarros y franceses, o Le Soterel, también tesorero del rey de Navarra (Spufford 1999), para que alguien ose decir que la moneda aún siendo del rey es interés del pueblo y con el debe contar para alterarla, en el espacio leonés por las necesidades económicas y desde una institución práctica se estaba cediendo parcialmente esa soberanía omnímoda aún cuando solo fuera por siete años, poco se sospechaba desde la mayordomía y cancillería del rey Alfonso, que ese hecho excepcional se iba a convertir en una figura impositiva estable, la más emblemática del reino, durante siglos.

El maravedí de oro se dejaría de acuñar en reinados sucesivos pero ya se mantendrá como unidad de cuenta reflejando la progresiva devaluación (Fuentes Ganzo 2000a: tabla p. 22).

La crisis monetaria llegará a su ápice en el reinado de Alfonso X, llevando los apuros económicos del rey al caos monetario a Castilla, que acuñaría monedas de necesidad sin apenas valor intrínseco, por ejemplo en 1252 el maravedí de cuenta ya equivalía a 120 dineros leoneses y a 112 burgaleses y en 1265 los dineros pepiones de Toledo de la guerra llegan al ínfimo valor de 180 por maravedí de cuenta (Pellicer 1999: tablas).

Dando un gran salto cronológico otro momento especialmente caótico fue el acceso al trono del primer Trastamara Enrique II en 1366, entonces la dobla ya está consolidada como divisa de oro, pero se seguía 
manteniendo el maravedí de cuenta. Al real de plata de buena ley de su antecesor Pedro I se le valuaba en tres maravedís, por las necesidades de pagos a los tropas mercenarias de Duguesclin, Enrique II idea una colosal falsificación oficial, haciendo acuñar reales de idéntica factura y tipología que los de plata pero en vellón desde 1366 al mismo valor de tres maravedís, valor que confirma en las ordenanzas de 1369 (Fuentes Ganzo 2000a), e incluso creó una moneda nueva también en vellón, el cruzado, de valor de $1 / 3$ del real, por tanto de un maravedí, con lo que volvía a coincidir el maravedí de cuenta con una moneda física en esta ocasión de vellón. Atendidas sus perentorias necesidades económicas y licenciadas las tropas extranjeras el rey procederá a un primer intento de reordenación económica devaluando $1 / 3$ la moneda con lo que el real de vellón pasaba a valer 1 maravedí y el cruzado un tercio por tanto dos cornados y tres dineros; por fin en las ordenanzas de Medina de 1373 recuperará la acuñación del real fuerte de plata al valor de 3 maravedís.

Una última fase especialmente significativa es la que se dará a finales del reinado de Enrique IV en el período 1462-68, tras una de relativa estabilidad en el largo periodo 1429-62, en que "la moneda decayó radical y verticalmente" (Mackay 1980).

En definitiva, el medievo castellano, conoció las primeras monedas fiduciarias que tenían o al menos pretendían tener un valor superior al nominal, de los que el ejemplo paradigmático es el maravedí, primero moneda real y tangible como divisa fuerte de oro, que pasaría en poco medios de medio siglo a ser moneda de cuenta para el sistema monetario castellano durante todo el medievo y la modernidad, y que ocasionalmente coincidiría con monedas efectivas de plata o vellón, pero alguien me dirá en qué se parecen el formidable maravedí de oro del siglo XII a los dos maravedís de vellón de Enrique II, o a la pieza menor de cobre que el siglo XVII era un maravedí.

Una de las singularidades de la historia monetaria de León es que fue uno de los territorios menos feudalizados de la Europa coetánea; si uno de los rasgos caracterizadores del feudalismo es la parcelación del poder político (Pérez-Prendes) en el reino, el ius moneta o poder sobre la moneda resultaba infisurable, a diferencia de Francia donde acuñan y emiten su moneda nobles, obispos y abades, por lo que quedaban escasos resquicios feudales. La moneda a decir del Fuero Viejo de Castilla es una de las tres cosas que pertenece en "sennorío al rey", es por tanto facultad propia e inenajenable del monarca. 
Es cierto, sin embargo, que el rey podía ceder o privilegiar a favor de un tercero el hecho físico de la emisión de "su" moneda (ejemplos tempranos tenemos en la mención de moneta urbis y moneta regis del Fuero de León -probablemente en una interpolación tardía del siglo XI sobre el texto de 1017-, o los tempranos privilegios a favor de las iglesias de Lugo o Santiago (Rueda 1991), generando rentas a favor del concesionario, generalmente un prelado, pero esta concesión siempre se condicionaba a:

a) Que la emisión se hace en nombre del rey, se efigia a éste o al emblema de su reino, e incluso se pone su nombre en el exergo, el obispo no emite moneda propia, emite la única moneda posible, la moneda del rey, incluso en ejemplos más tardíos de concesión de monedas a favor de señores laicos en una Castilla más secularizada, como por ejemplo las emisiones del Conde de Benavente en Benavente y Villalón, cuyo señorío es un estado dentro del Estado las monedas se emiten a nombre del rey Enrique IV.

b) El rey a través de sus oficiales y del privilegio otorgante regula y disciplina las condiciones de emisión, finuras, ligas, peso y tipología de las monedas, de hecho todos los pasos del proceso son vigilados por guardias.

Aún con todo, falsificadores y falsarios sobre la moneda existieron siempre y fueron implacablemente perseguidos por la ira regia, mereciendo los castigos más rigurosos, como en tiempos de Fernando III que se los introducía en una hoya hirviendo (Menéndez y Pelayo); en el Fuero Real datable hacia 1255 se prevé la pena de muerte para el falsificador de moneda y la confiscación de la mitad de sus bienes al que se atreviese a cercenarla para apropiarse de metal (F.R. IV,XII,7). Incluso en otros reinos limítrofes vieron posibilidades de falsificar monedas de necesidad o débiles del reino vecino con un valor nominal muy superior al real, con el doble efecto de menoscabar el prestigio del reino limítrofe introduciendo en el mismo "mala moneda" y de obtener ganancias fabulosas; uno de los ejemplos más emblemáticos es la falsificación que ordena hacer Pedro IV, rey de Aragón, de los reales malos de vellón de Enrique II, a los que aludimos, en época de la Guerra Civil en Castilla entre Pedro I y Enrique II, el 12 de diciembre de 1366.

Por parte de los Reyes y en el supuesto ejercicio de su autoridad y derecho omnímodo sobre la moneda surgió también una práctica 
falsificatoria oficial que era la renovatio moneta, convirtiéndose en manipuladores y falsificadores de su propia moneda por el debilitamiento intencionado de la misma conservando su valor oficial, pero reduciendo su valor intrínseco al empobrecerla reduciendo en su liga la proporción de metal precioso, haciendo que se hablase de "dineros negros" y como generalmente estaban ligados a un hecho bélico "dineros de la guerra" en tiempos de Alfonso X, o incluso en Francia "denarium corruptissimum" (Spufford 2000 y también Bompaire 2000).

El debate doctrinal sobre la legitimidad del rey para la renovatio moneta surgirá en el siglo XIII con la glosa, que en principio se decantarán a favor de esa capacidad del rey como una prerrogativa más de su ius moneta, tendrá una figura capital en el siglo XIV con Nicolas de Oresme que procedía del colegio de administradores de Navarra, y llegará en territorios hispánicos hasta principios del siglo XVII con el padre Mariana (1607). Como decíamos la glosa y los textos legislativos autorizaban al rey a disponer sobre la moneda en la forma que quisiere, la reiterada mención del Fuero Viejo del sennorio del rey sobre la moneda, o las menciones en las cortes francesas de San Luis hacia 1265 "...faciat ibi monetam suam turonnse ... cursidalem per totum regnum" (Bompaire 2000), es decir el gros de plata que se acuñaba en Francia, en Tours, era moneda del rey y no local circulando en todo el reino. La quiebra como anticipábamos se va a producir a mediados del siglo XIV hacia, 1355, de la mano de Nicolas de Oresme, en su tratado De moneta, que aún reconociendo esa facultad al rey sobre la moneda, postulaba, digámoslo en términos modernos, su interés público, y por tanto limitaba esa facultad (Spufford 2000).

Sin embargo y a pesar de este tardío reconocimiento en el siglo XIV, en el espacio leonés, en 1202, que paradójicamente en materia de moneda entonces es el reducto más regalista de Europa, se ha producido un hecho capital en las Cortes de Benavente, la regulación de moneda forera en que el rey pacta un impuesto la moneda forera autolimitando su derecho a quebrar moneda durante siete años a cambio de un impuesto o pecho (Fuentes Ganzo 1996 y 2000).

Alfonso IX debió recibir las protestas de los concejos y del pueblo, tras la intensa alteración de moneda y devaluación que se ve obligado a realizar a finales del siglo XII, por lo que vende esa capacidad por siete años, a un maravedí por pechero, es decir unos 90 dineros de vellón de entonces, hasta el punto de que tras la unificación definitiva tres décadas después, paso a convertirse en un impuesto estructural para 
Castilla y León unificados, y de singular regularidad por los cuadernos de Cortes que conocemos, salvo su uso abusivo en tiempos de Alfonso X. De forma que cuando en Europa se esta debatiendo la licitud de la alteración de moneda por el rey y su pactabilidad o sometimiento al interés general, en Castilla y León y desde las asambleas estamentales que eran las Cortes se estaba haciendo por la vía de hecho desde el despuntar del siglo XIII.

\section{LA UNIÓN CON CASTILLA Y LA CIRCULACIÓN MONETARIA}

\section{DURANTE LOS SIGLOS XIII-XIV. LAS FERIAS}

Uno de los momentos álgidos de la historia medieval peninsular, pero que simultáneamente marca el inicio del declive del reino leonés, se va a producir en diciembre de 1230: La unificación definitiva de Castilla y León en una curiosa curia binacional, probablemente la última gran jugada política de la hija del castellano Alfonso VIII, y primera esposa del leonés Alfonso IX, Berenguela. Trece años lleva gobernando en Castilla su hijo Fernando III. En Benavente se reúnen las dos esposas de Alfonso IX, Berenguela de Castilla y Teresa de Portugal, el rey Fernando hijo de la castellana y las infantas Sancha y Dulce o Aldonza sus hermanastras hijas de la portuguesa, a favor de las cuáles había otorgado testamento. La extraña curia no deja lugar a dudas en cuanto a su composición, además están, al decir de la crónica, los primados de los dos reinos, el arzobispo toledano y el compostelano, "et barones multis et consiliis".

$\mathrm{Y}$, ¿cómo no?, al final como casi todo cuestión de "dinero y moneda", se resolvería por un pacto en que las infantas cedían sus derechos dinásticos a favor de Fernando III a cambio de una pensión vitalicia de treinta mil ducados de a setenta cada año, según dice erróneamente la Crónica, aunque evidentemente se trata de un documento de redacción posterior e interpolado en la mención monetaria, cuando la divisa vigente parar el oro sigue siendo el maravedí -aún el propio Fernando III no habría acuñado la primera dobla hispánica, y desde luego aún no se podía hablar de ducados-, por lo que se debe leer 30.000 maravedís de a setenta dineros cada uno, mención que confirma el documento del tratado de Benavente de los Archivos Vaticanos, regesta de Gregorio IX que publicó Julio González (1980: t. II, doc. 270): "In primis assignat eis (a éstas, las infantas) triginta milia morbotinorum singulis annis percipiendorum toto tempore vita earum".

Desde ese momento, León quedaría supeditado a Castilla, la cancillería de León que estaba vinculada al arzobispado de Santiago se 
conservará por poco tiempo, terminando vinculándose a la de Castilla que ostentaba el primado castellano, arzobispo de Toledo; todo esto se refleja muy bien en la diplomática (González 1980). En las columnas de confirmantes aparecerá en primer lugar "Rodericus, toletanus sedis episcopus, Hipaniarum primus", luego la relación de obispos castellanos y en segundo lugar protocolariamente, los leoneses encabezados por el arzobispo de Santiago. Igualmente se aprecia como en los primeros años tras la unificación, aunque más propiamente en principio fue una federación de reinos bajo una misma corona, casi toda la producción diplomática procede de espacios leoneses, lo que evidencia la astuta presencia del rey en los primeros años tras la unificación, más o menos hasta el año 1236, para después casi desaparecer los diplomas en tierras leonesas.

En el aspecto monetario, aunque el numerario de Fernando III no es de los más conocidos salvo la acuñación de las primeras doblas en oro, parece que hoy es convención admitir que aún no se produce la unificación heráldica en las monedas, y de hecho se siguen acuñando dineros leoneses de tipología parecida a los últimos dineros de Alfonso IX, "MONETA LEGIONIS" (con tipo de leones bajo el árbol de Segorbe) y probablemente en Castilla se siguieron acuñando dineros inmovilizados similares a los de Alfonso VIII, manteniendo los dos tipos monetarios y los dos sistemas de cuenta.

Habrá que esperar a la llegada al trono de Alfonso X, en la segunda mitad del XIII, para que ya se combinen en los tipos monetarios los motivos heráldicos de los reinos apareciendo por primera vez en las monedas los escudos cuartelados de Castilla y León.

El reinado de Alfonso $X$, a pesar de haberse convertido ya en un reino periférico y menos relevante del reino unificado, en lo económico y en lo monetario, reviste su importancia, ya que en este tiempo el rey concede Ferias a las villas del reino, se trata de conformidad con la opinión de Ladero Quesada, de la segunda generación de ferias castellanas y leonesas, que aglutinan territorios económicos sobre todo en Galicia y al este de Portugal.

Esta circunstancia económica necesariamente hubo de reflejarse en la circulación monetaria por dos motivos:

1) De carácter general con un incremento de la monetización de la economía dada la mayor madurez de las estructuras productivas en Castilla desde mediados del siglo XIII, y 
2) De carácter local en los municipios, ya que la concesión de Feria dinamizaría la vidas económicas de las principales villas y ciudades y consiguientemente la afluencia y circulación de moneda.

Figura 5: El llamado cuarto de maravedí de plata de Alfonso X, posible maravedí de la guerra, que se custodia en el M.A.N., 1994/50/3949. Igual que los dineros llamados de seis líneas, con escudos cuartelados de Castilla y León y retrato de Alfonso $X$ con la misma heráldica de castillos y leones en la túnica real del Libro de Dados.
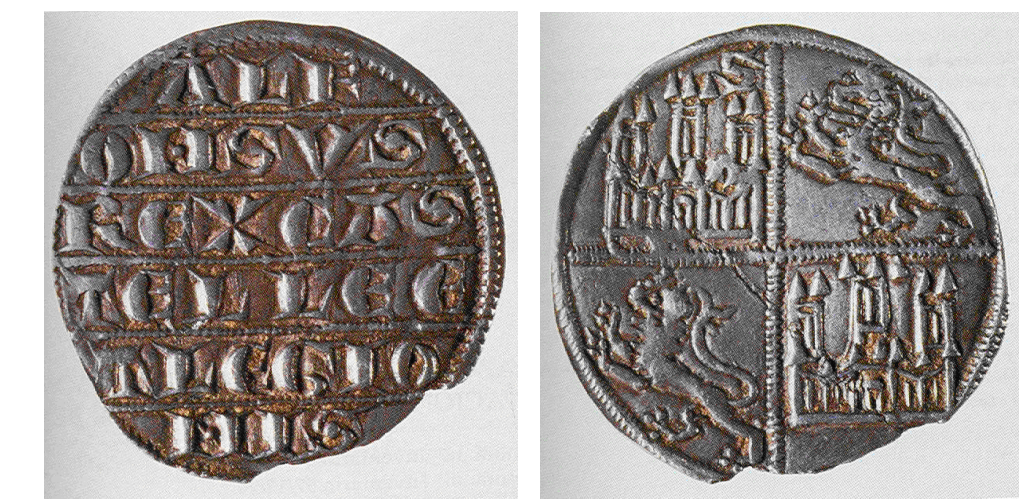

Fotografía gentileza del M.A.N.

De hecho, en este periodo, hay que datar los más remotos hallazgos contextuados de moneda medieval, como piezas halladas de Alfonso $X$ sin marca de Ceca así como dineros de la guerra del mismo monarca.

Es justamente en este momento histórico cuando se va a producir un apogeo de las Ferias, produciéndose en los Reinos cristianos un primer ciclo ferial entre los siglos XII e inicios del XV (Ladero Quesada 1994) cuyo desarrollo inicial en el territorio leonés hay que vincularlo a los reinados de Fernando II y Alfonso IX y el desarrollo del camino de Santiago: Ferias de Sahagún, 1155, Mondoñedo, Milmiada (1199), Villalón (1200), o Cáceres -entonces "extremadura" leonesa- en 1229. Con un enorme desarrollo en la época de Alfonso X con la unión de reinos, la propia Feria de León no está documentada hasta 1270 ó la de otro importante enclave leonés, Salamanca en 1272 (Ladero 1994: 110).

La actividad Ferial estaba vinculada al contexto repoblador inicialmente pero su impulso en la época de Alfonso $X$ tiene obvias explicaciones fiscales, de ahí su importancia en la época donde los impuestos sobre mercancías comienzan a cobrar enorme significado; es 
más si observamos las regulaciones feriales hasta el siglo XV, incluso las tardías, se limitan prácticamente a contener normativa fiscal sobre las transacciones o una suerte de impuesto a las importaciones a favor del rey o del señor que la otorga, por poner un ejemplo en territorio leonés, las ordenanzas de la Feria de Bejar en 1452 va regulando las tasas por ejemplo los paños de Brujas y Londres que se vendan por varas pagarían 35 maravedíes cada mercader por "millar de la dicha ropa" (AHN, Osuna, leg. 216,2) y los "paños que se fazen en Castilla..." pagarían 28 maravedíes.

Evidentemente la proliferación de ferias francas favoreció el incremento del comercio, que se unió al incremento de la circulación monetaria concediendo exenciones de portazgo, esto se unió a la consolidación de la Mesta que favoreció el negocio pecuario e interregional (Ladero 1994).

Desde el siglo XIV se aprecia en la documentación una difusión de los instrumentos de crédito: "se organizaban pagos y concertaban cambios ante escribano público" según rezan memoriales de la época con el inicio de la afluencia de comerciantes extranjeros. Sobre las implicaciones para el sistema económico se ha reflexionado que jugaron un papel de estimulo inicial para el desarrollo de los intercambios económicos (Carlé 1954), vinculado más a áreas rurales que a urbanas (Ladero 1994) y en relación con las "transformaciones hacendísticas" (Carande 1965). Tardíamente el sistema financiero, la Banca y los contratos de pago aplazado se vincularán a las Ferias, pero en este caso en rigor solo se puede hablar de una gran Feria como tal, la de Medina del Campo desde finales del siglo XV, impulsada decididamente por la nueva monarquía y el nuevo estado gestado por los Reyes Católicos como veremos.

5. EL OCASO DEL REALENGO: MONEDA EN EL XIV, DE LA ESTABILIDAD DE LA PRIMERA MITAD A LA CRISIS TRASTAMARA

El territorio leonés, en las actuales provincias de León, Zamora y Salamanca, ha proporcionado importantes hallazgos arqueológicos cuantitativos y cualitativos para definir la circulación monetaria en tres momentos fundamentales: El Tesoro de Coreses hallado en las inmediaciones de Zamora, donde se localizaron 1017 dineros de Alfonso IX (estudiados por A. Orol), nos da una idea muy exacta de la circulación monetaria en el tránsito del siglo XII al XIII, coincidiendo con las cortes de 1202 . El tesoro encontrado C/ obispo Grau en Astorga en 1992 con 1805 monedas (que se conserva en el Museo de León, del que hizo una primera 
preclasificación Mercedes Rueda, y del que recientemente hemos concluido su estudio y catalogación) con piezas de Alfonso X, Sancho IV, Fernando IV y sobre todo mas de un millar de monedas de Alfonso XI) nos proporciona una idea muy cabal de la circulación monetaria en territorios del reino leonés en la primera mitad del siglo XIV); y finalmente el tesoro de la Plaza de Arias Gonzalo en pleno casco de Zamora en 1999 (Museo de Zamora) piezas entre las que hay numerario foráneo de oro con moneda castellana desde Pedro I, pero fundamentalmente de Enrique III, y Juan II, nos da una idea muy cabal de la circulación monetaria en estos espacios leoneses en las primeras décadas del siglo XV.

Figura 6: Sancho IV Cornado, anverso y reverso ceca de León. Museo de León, nº 1992-15,II,64
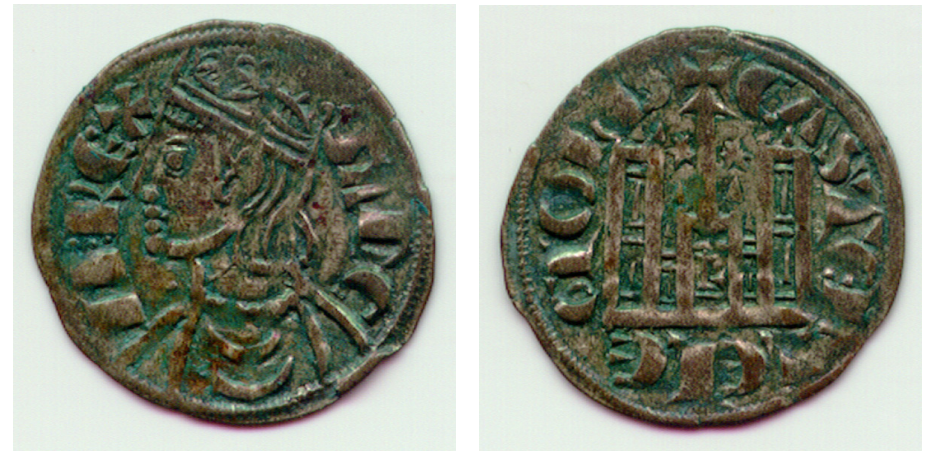

Siguiendo el hilo de nuestro discurso, podemos decir que a pesar de su excentricidad en el espacio unificado de León y Castilla, cada vez más amplio por los avances de la reconquista y la reunificación, sí conservo un cierto protagonismo desde finales del XIII y principios del XIV, buena prueba de ello es su activa presencia en las hermandades de las minorías de Fernando IV y Alfonso XI: Diversas villas leonesas participan en la hermandad leonesa de 1282 con Sancho IV, en la de las Cortes de Valladolid de 1295, en la hermandad leonesa de seguridad de 1312, en una hermandad política sumamente restringida con los infantes don Juan y don Felipe en 1313 -con tan solo León, Zamora, Astorga, Benavente y Mansilla- y en la general de 1315 (Fuentes Ganzo 1998c).

Pero con todo, ya se van percibiendo síntomas de agotamiento en el reino, por ejemplo es significativo el caso de Benavente a finales del siglo XIII el privilegio de Sancho IV: "e porque nos ficieron entender que la villa era muy despoblada", el rey para estimular y favorecer 
nuevas asentamientos y avecindamientos en la leonesa villa de Benavente establecía una reducción fiscal a cada vecino de la tercera parte del impuesto: "que se fagan tres en fuero". En parecidos términos se expresa al final de su reinado en 1293, tratando de incentivar el paso de lugares de behetría a realengo en villas próximas al alfoz, en este segundo privilegio además establece una interesante mención monetaria, al establecer un pecho sancionador para el que quebrantare el privilegio: "en coto mill maravedís de la moneda nueua", evidentemente esta moneda nueva se refiere a la que ha acuñado Sancho IV conforme al Ordenamiento de Vitoria (Hernández-Canut 1997), de sus cornados y sus "meajas coronadas" porque en 1282, aún infante en rebelión contra su padre había retornado por el conocido privilegio que se conserva en el Archivo General de Simancas, a los leoneses, burgaleses y salamanqueses previos a Alfonso $\mathrm{X}$, es decir a la buena moneda de Fernando III.

Figura 7: Cornado Alfonso XI León. Museo de León, Junta de Castilla y León, no 1992,15,IV-225
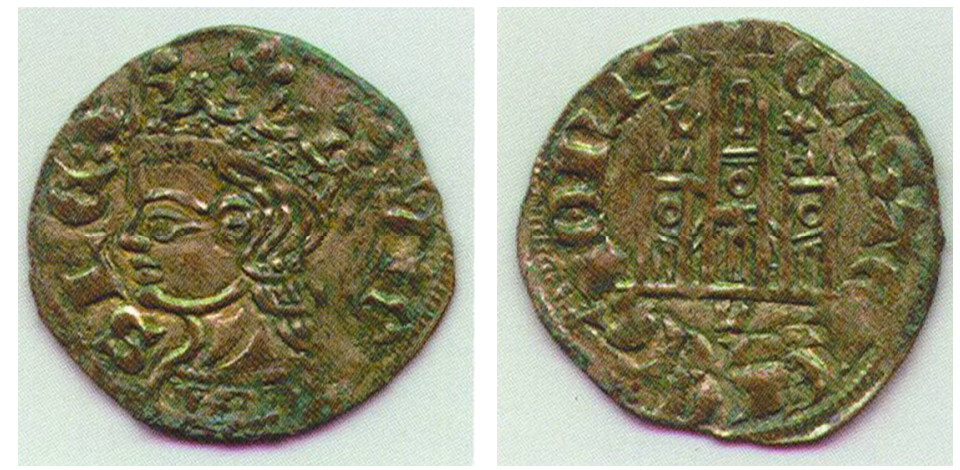

La llegada al trono de Enrique II, y sobre todo la guerra civil entre petristas y trastamaristas (1366-69) que se saldo con la muerte de Pedro I a manos del propio Enrique II en los campos de Montiel, trajo un marasmo monetario a Castilla que no se conocía desde los tiempos de Alfonso $\mathrm{X}$, siendo en nuestra opinión una de las cuatro grandes crisis con brutales quiebras monetarias de León y Castilla a lo largo de los siglos medievales, a saber:

1) El quinquenio de crisis de finales del siglo XII con Alfonso IX (1196-1202) en época de la vigencia del maravedí de oro, que llevó a la depreciación del maravedí de cuenta leonés (a valer más dineros) y a la moneda forera. 
2) Las dos últimas décadas del reinado de Alfonso $X$ con la aparición de los dineros negros y maravedís prietos (1260-1282).

3) La Crisis de Guerra civil y comienzos del reinado de Enrique II, hasta la estabilización monetaria de las Cortes de Toro de 1373 que supuso la quiebra en vellón del real de plata de buena ley, propiciando falsificaciones en Aragón, como vimos (1366-1373).

4) $Y$ finalmente la crisis monetaria durante la década de los 60 del siglo XV con Enrique II en que el rey concedió sinnúmero de casa de moneda a nobles en pago de mercedes que quebraron la moneda fuerte de vellón de más circulación de entonces: el cuarto de real (1460-71).

Figura 8: Cruzado 1369-70 valor 1 maravedí. Acuñado en León: L/E/O/N.

Museo León, $n^{\circ}$ Inventario: 2424b
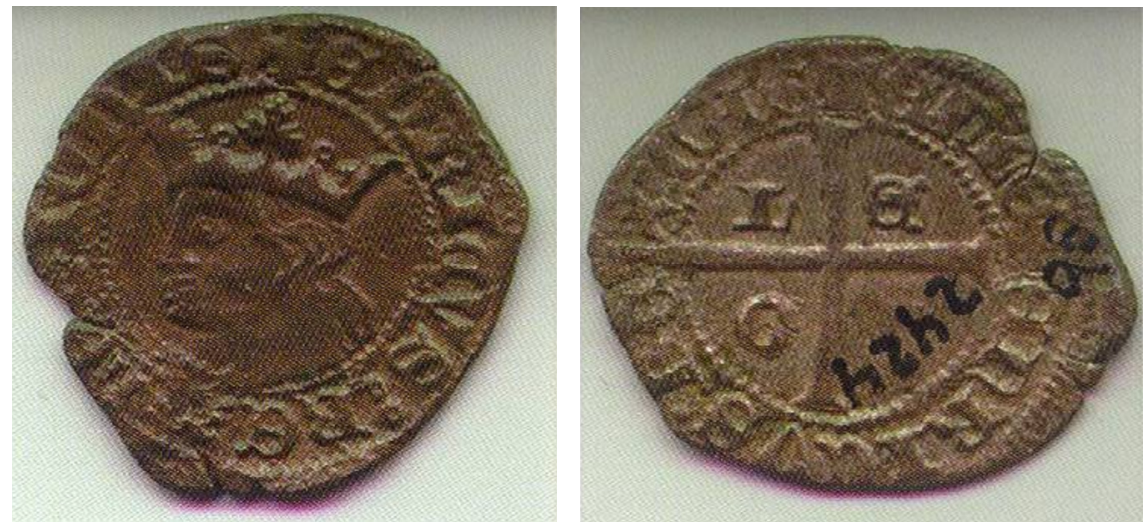

Además en el tiempo de Enrique II se crearon nuevas monedas, fundamentalmente el cruzado en 1369 al que en principio se dio un valor de un maravedí.

No es momento ni lugar para extendernos sobre las reformas monetarias y numerario de Enrique II que ya hemos desarrollado en otro trabajo (Fuentes Ganzo 2000b), por lo que nos limitaremos a remitirnos al mismo.

Para León por esos años, en 1370, el rey Enrique II vuelve a emitir privilegio que evidencia la crisis local, en términos que nos recuerdan los de Sancho IV un siglo antes, aunque en esta ocasión está 
pagando los servicios prestados por la ciudad en la guerra civil, en que el concejo se había mostrado trastamarista ya que añade "por el danno que abedes rreçebido por nuestro serviçio".

\section{CATÓLICOS}

\section{LAS ÚLTIMAS MONEDAS MEDIEVALES DURANTE LOS REYES}

Tras tiempos turbulentos, a finales del siglo $X V$ en que pretenden la corona de Castilla Alfonso de Avila y Alfonso $V$ de Portugal frente a Enrique IV, y el propio Alfonso de Portugal y Juana "la Beltraneja" frente a la hija de Juan II, Isabel la Católica, que se va a hacer con el trono, con la ayuda inestimable de su sagaz marido el rey de Aragón y Sicilia, el personaje con más poder en Italia que junto con Cesar Borgia inspirará a Maquiavelo la redacción de El Príncipe.

El salto cualitativo va a ser enorme, los Reyes Católicos partirán de una federación de reinos medievales, para terminar construyendo el primer estado moderno y crear otra Hispania, "Nueva" y más dilatada al otro lado del Océano. Lo mismo acaecerá en lo numismático, hay un antes y un después de las Cortes de Medina de 1497, un lustro después del descubrimiento, en que ponen el corolario numismático al nuevo estado que se ha ido forjando desde las Cortes de Toledo de 1480, en 1497 reforman la moneda en pesos y tipos, creando la moneda moderna del primer estado moderno, antes los tipos, pesos y ligas de las monedas eran medievales, desde entonces una moneda moderna que ya no se reformará otra vez hasta 1566.

Aunque no se conoce la fecha exacta para el inicio de las acuñaciones al principio de su reinado si consta una carta enviada a Toledo por los Reyes el 23 de mayo de 1475 (Beltrán 1952), mandando estampar en las monedas sus bustos (que se hacía regular e ininterrumpidamente desde el primer Trastamara), sus iniciales coronadas (que se hacía en los reales desde Pedro I) y las armas de ambos reinos por separado en los reales, tal como se hizo en las primeras acuñaciones de León y Castilla hasta Alfonso $X$ que unificó en los tipos monetarios las armas de León y Castilla, así se haría en principio por sus católicas majestades hasta que también durante su reinado fundieron los cuarteles de los dos reinos en un escudo "panhispánico". La única inicial innovación tipológica fue insertar en las acuñaciones de aquellos primeros reales medievales las armas de Castilla de León, Castilla y Aragón en el águila de San Juan, por cuyo Evangelio y Apocalipsis sentía especial predilección la 
reina Isabel (Fuentes Ganzo 1998b). En principio hacen acuñar oro fino y plata de ley de 11 dineros y cuatro granos, como en las últimas acuñaciones de Enrique IV, no acuñando nada en vellón, para aprovechar el abundante numerario que aún circulaba por Castilla de anteriores reinados, partiendo en el oro del doble castellano o "Doble excelente" (es decir la tradicional dobla) y acuñando en plata reales, medios y cuartos de real. Para ello aprovecharán las seis cecas reales (de la que solo quedó una en el antiguo territorio leonés: la gallega de Coruña) tras la racionalización de las casas de moneda de Enrique IV, volviendo a acuñar en Segovia y añadiendo tan solo Granada tras su conquista. Estas serán las primeras monedas, aún medievales, de los Reyes Católicos, manteniendo la inicial circulación del vellón medieval y acuñando con pesos y ligas medievales plata y oro con sus tipos.

Para las cecas tradicionales del viejo reino de León supuso la definitiva desaparición de las mismas, el centro de gravedad del estado unificado, con la segunda unificación volvía a desplazarse más aún al occidente peninsular, quedando solo una noroccidental del viejo espacio leonés, la ceca gallega de Coruña; ya nunca en León se volverá a acuñar, y mucho menos en otros territorios donde aún se había hecho durante el siglo XV (Santiago, Salamanca, Zamora, Tuy, Milmiada, Benavente o Ciudad Rodrigo...).

7. LA PRAGMÁTICA DE MEDINA DEL CAMPO DE 1497. LA APARICIÓN DE LA MONEDA MODERNA Y EL OCASO DE LAS CECAS LEONESAS

En las Cortes de Medina, el 13 de junio de 1497, los Reyes Católicos, los últimos monarcas medievales y primeros modernos de España y de Europa, revolucionarán la legislación de moneda, cuando llevaban más de dos décadas en el trono, iniciando la moneda moderna. Una primera dimensión de su reforma moneda, fue su pretensión de universalidad, de que se aplicase en todos sus estados, con la proyección que ya tenían -Castilla en dos continentes y Aragón como potencia mediterránea-, ya la moneda se vinculará a la Corona y no a los Reinos:

ordenamos que en cada una de nuestras casas de moneda... (Heiss).

Una segunda dimensión del nuevo ordenamiento de la moneda será el establecimiento del Ducado como divisa del oro, así lo razonan los monarcas: "porque se a encontrado que las monedas de los ducados son 
las más comunes en todos los reinos i provincias de la cristiandad, i más empleadas en todos los contratos". De esta forma se implantaba en los territorios de la Corona, constituida en incipiente potencia hegemónica de Europa el Ducado de origen veneciano, a la que en su versión hispánica los monarcas darán un nombre sumamente significativo: "excelente de la granada", por lo que ordenan: "...se labre moneda de oro fino de lei de veinti tres quilates i tres cuartos largos i no menos, $i$ de esa lei se labren monedas que se llame excelente de la granada, que sea de peso de setenta i cinco piezas e un tercio por marco" (Ley I, Pragmática de 1497).

Figura 9: Real de Plata, de los Reyes Católicos, posterior a la Pragmática de Medina del Campo. Acuñada en Burgos "B", circuló en León con posterioridad a la pragmática.

Museo de León, $n^{\circ}$ Inventario 2462
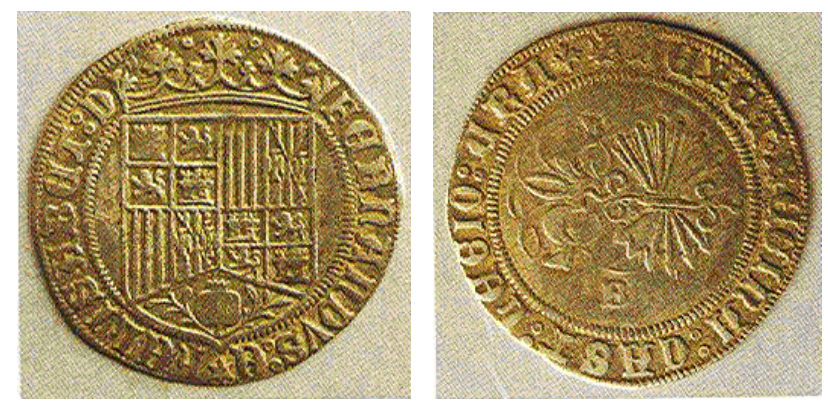

Para el metal argénteo mantendrán el real (tallando 77 piezas por marco), pero cambiando la tipología con el simbolismo del Yugo y las flechas entrelazados en su anverso y fundiendo en reverso en un escudo integrado las armas de Castilla y Aragón, que acababa con el tipo del primer real que acuñaron, indudablemente "medieval", que labraron con heráldica de un reino en anverso y del otro en reverso: " $i$ que en los reales se ponga de una parte nuestras armas reales (ya unificadas) e de otra las devisas del yugo de mi la reina i la devisa de las frechas de mi el rey".

Tal éxito tendrá la reforma que el ducado en la forma de excelente de la granada pronto pasará en la documentación a ser la unidad de cuenta de las operaciones económicas cuantiosas, tal como ya hizo notar Ramón de Carande (1967: t. II, p. 467, refiriéndose a los documentos ya desde 1504). De igual forma impondrán el ducado en los territorios italianos de Nápoles que conquistan en 1503, y en Navarra desde 1509, como ya hemos afirmado en otro lugar: la unificación de moneda respecto a 
la divisa de oro, tuvo más éxito que la unificación jurisdiccional (Fuentes Ganzo y Morán Martín 1998).

A la entusiasta afirmación de Nebrija: "Hispania tota, sibi restituta est", debía corresponder una nueva política monetaria, y sobre todo una nueva simbología que se plasmase propagandisticamente en las leyendas y tipos de las monedas con todo un programa humanístico simbólico, para ello se mezclaron sabiamente los viejos y los nuevos símbolos en las monedas -los medievales y los humanísticos-, al simbolismo medieval de la heráldica de los reinos, y de las iniciales coronadas como en anteriores monarcas " $Y$ " de Isabel y " $F$ " de Fernando en las monedas más corrientes, las blancas, se añadió:

a) El lema nebrijense de "TANTO MONTA", que se inspiraba en el mito del "nudo gordiano" de Alejandro Magno, expresando metafóricamente la igualdad de los Reinos federados.

b) El YUGO y las FLECHAS como abstracción simbólica de los reyes y sus iniciales: $Y$ y $F$.

c) El águila de San Juan, orlando primero el escudo de Castilla y luego el escudo de todos los reinos, el "hijo del Trueno", autor del Apocalipsis, generando un programa devocional que complacía a la Reina de Castilla.

d) El lema que acompaña al águila que cobija todas las armas de Castilla, León, Aragón, Navarra, Granada, Sicilia, Nápoles y las posesiones castellanas transoceánicas: "SUB VMBRA ALARUM TVARVM" (bajo la sombra de tus alas), que se acomodaba a la integración que pretenden los reyes y se refleja en el tipo y leyenda del exergo de excelentes y dobles excelentes.

e) Integración en los cuarteles heráldicos de la nueva monarquía (Castilla y León $-1^{\circ}$ y $3^{\circ}$ cuartel- y Aragón y Sicilia $-2^{\circ}$ y $4^{\circ}$-), hecho que anteriormente no se reflejó en los tipos de las monedas cuando la unificación de Castilla y León con Fernando III en 1230, hasta una generación después con Alfonso $X$.

f) La inserción progresiva de las nuevas perlas de la corona en el escudo heráldico de la monarquía (Granada en 1492 y las cadenas de Navarra en 1512).

Con este programa alegórico, integrador y unificador soportado fundamentalmente en una moneda, el ducado de oro, y con la 
restricción de cecas, ya conseguida por Enrique IV con las reformas de 1471 a 1473, poca cabida tenían en la modernidad las cecas leonesas del antiguo Reino. Únicamente en aquellos espacios se perpetuará la ceca de Coruña, interrumpiéndose el resto de las labores monetarias en los espacios leoneses durante el resto de la edad moderna, Austrias y Borbones no volverán a acuñar en León ni en sus territorios, con la excepción de Coruña.

Los territorios castellanos del reino saldrían algo mejor parados en tiempos de los Austrias en cuanto a cecas con Burgos, Valladolid, Cuenca, Granada, Sevilla y sobre todo el ingenio de Segovia, en cambio las casas de moneda en los territorios occidentales de la península (el viejo reino de León) no serían mas que un residuo histórico.

\section{BIBLIOGRAFÍA}

ALFARO AsINS, C. (1996) La moneda, algo más que dinero. Madrid: Museo Arqueológico Nacional.

ÁlVAREZ BuRgos, F. (1998) Catálogo de la moneda medieval castellanoleonesa (Siglos XI-XV). Madrid: Vico.

BARCELO, M. (1977) "Monedas visigodas en Hispania: estado de la cuestión y algunos problemas de metrología y organización de las emisiones", Numisma, $\mathrm{n}^{\circ}$ 23-24, pp. 147-9.

Beltrán MARTínez, A. (1983) Historia de la moneda española a través de cien piezas del museo de la Fábrica Nacional de moneda y timbre. Madrid: Vico Monteoliva.

- (1994) "El vellón español en el siglo XI", Crónica Numismática, 46, pp. 12-28.

Beltrán Villagrasa, P. (1972) Obra completa. Numismática de la Edad Media y los Reyes Católicos. Zaragoza: Institución Fernando el Católico.

BeltrÁN, A. y P. (1952) "Numismática de los Reyes Católicos", V Congreso de la Corona de Aragón, Zaragoza.

BompaIRE, M. (2000) "Monnaies et politiques monétaires en France (XIle.XVe siècle)", Moneda y monedas en la Europa occidental (Siglos XIIXV), XXVI Semana de Estudios medievales de Estella, Pamplona.

CARLe, M.C. (1954) "Mercaderes en Castilla", Cuadernos de Historia de España, XXI y XXII, Buenos Aires. 
CARMONA DE los SANTOS, M. (1996) Manual de sigilografía. Norma técnica 5 de la Subdirección General de Archivos estatales, $M^{\circ}$ de Educación y Cultura, Madrid.

CAStillo CáCERES, F. (1990) "Los símbolos del poder real en las monedas de Pedro I", Numisma, n 39, pp. 222-7.

- (1994) "Aproximación a las monedas de Alfonso de Castilla (1465-1468)", Actas del VIII Congreso Nacional de Numismática, Avilés.

CAunedo del Potro, B. y R. Córdoba de la LlaVe (2000) El arte del alguarismo. Un libro castellano de aritmética comercial y de ensayo de moneda del siglo XIV. Valladolid: Junta de Castilla y León.

FERRO TAVARES, M.J. (1974) Estudos de historia moetaria portuguesa (1383-1483). Lisboa: Universidade Aberta.

Figuerola, M. y L. Grau (1998) Moneta legionis. León: Junta de Castilla y León, Museo de León.

Fuentes Ganzo, E. (1996a) Las Cortes de Benavente: El siglo de oro de una ciudad leonesa. Madrid: Fomento Esla.

- (1996b) "La acuñación del Conde de Benavente en el siglo XV", Brigecio, 6, pp. 187-202.

- (1997) "Breve historia de la moneda de Zamora", Studia zamorensia, IV, pp. 45-64.

- (1998a) "La circulación monetaria foránea en el reino de León Medieval: I La moneda portuguesa", Actas del X Congreso Nacional de Numismática. Albacete.

- (1998b) "La moneda como símbolo e instrumento de legitimación y propaganda", Gaceta Numismática, 131, Barcelona.

- (1998c) "Las hermandades leonesas (1282-1325): Presencia y participación de concejos. El singular caso de Benavente", Brigecio, 8.

- (2000a) "Ordenamiento de moneda y maravedí de oro en las Cortes de 1202", Gaceta Numismática, 136, Barcelona.

- (2000b) "Una cofradía menestral en el señorío: Santa Marta de los çapateros en 1459 en Las relaciones hispano-portuguesas en la Baja Edad Media", Actas del VI Centenario del Condado de Benavente, Benavente.

- (2000c) "De doblas a meajas: Las acuñaciones y reformas de Enrique II", Brigecio, 10.

- y R. MORÁN MARTín (1999) "Ordenamiento, legitimación y potestad normativa: Justicia y moneda", VV.AA., Orígenes de la monarquía hispánica: Propaganda y legitimación ca. 1400-1520. Madrid: Dyckinson. 
GAUTIER D'AlCHE, J. (1976) "La politique monétaire d'Alphonso X", Cuadernos de Historia de España, 69, Buenos Aires.

GIL FARRÉs, O. (1976) Historia de la moneda española. Madrid: Gil Farres.

Gual Camarena, M. (1981) El primer manual hispánico de mercadería. Barcelona: CSIC.

GUCLIERI, A. (1974) Catálogo de sellos de la sección de sigilografía del Archivo Histórico Nacional. Madrid.

HERNÁNDEZ-CANUT Y FERNÁNDEZ-ESPAÑA, L. (1997) "Las acuñaciones monetarias de Sancho IV según el ordenamiento de Vitoria", Gaceta Numismática, 127.

- (2000) "El abadengo de Sahagún. Vestigios de una manifestación monetaria feudal en los reinos de Castilla y León durante el siglo XII", Gaceta Numismática, 137.

LADERO QUESADA, M.A. (1988) "La política monetaria en Castilla. 1369-1497", En la España Medieval,11.

- (1994) Las Ferias de Castilla. Siglos XII a XV. Madrid: Comité español de Ciencias históricas.

- (1998) "Las reformas fiscales y monetarias de Alfonso X como base del estado moderno", Alfonso X. Aportaciones de un rey castellano a la construcción de Europa, Murcia.

- (2000) "Monedas y políticas monetarias en la Corona de Castilla (siglos XIII-XV)", Moneda y monedas en la Europa occidental (Siglos XII-XV), XXVI Semana de Estudios medievales de Estella, Pamplona.

LHOTKA, J.F. y P.K. ANDERSON (1989) Survey of Medieval Iberian Coinages. New York: Sandford.

MACKAY, A. (1980) "Las alteraciones monetarias en la Castilla de siglo XV. Moneda de cuenta y la historia Política", En la España Medieval.

MARIANA, Padre J. (1987) Tratado y discurso sobre la moneda de vellón (de moneta mutatione), Colonia 1607. Madrid: Edic. Atlas.

MENÉNDEZ PELAYO, M. (1981) Historia de los heterodoxos españoles. Madrid: BAE.

MetCALF, D.M. (1979) Coinage in South-Eastern Europe, 820-1936. Londres.

- (1988) "A Parcel of Coins of Alfonso VI of León (1073-1109)", Problems of Medieval Coinage in the Iberian Area, III., Santarem.

MORÁN MARTín, R. y E. FUENTES GANZO (1999) "Ordenamiento, legitimación y potestad normativa: Justicia y moneda", VV.AA., Orígenes de la 
monarquía hispánica: Propaganda y legitimación ca. 1400-1520. Madrid: Dyckinson.

Mozo Monroy, M. (1998-9) "La moneda medieval de Castilla y León. Bibliografía general", Medievalismo, 8 y 9, Madrid.

ORESME, N. (1981) "Tractatus de origine et natura, iure et mutationibus monetarium", Hernando, J. (edic.) Acta historica et archaelogica medievalia, 2.

Orol Penas, A. (1982) Acuñaciones de Alfonso IX. Madrid: Vico.

PÉrez-PRENDES MuÑoz de ARRAJO, J.M. (2000) "Moneda y Cortes", Dinero, moneda y crédito en la monarquía hispánica. Madrid: M. Pons.

- (2000) Cortes de Castilla de Castilla y León. Madrid: Univ. Complutense.

Riera Melis, A. (2000) "Monedas y mercaderes en la Edad Media: El Mediterráneo occidental", Moneda y monedas en la Europa occidental (Siglos XII-XV), XXVI Semana de Estudios medievales de Estella, Pamplona.

ROMA VALdÉs, A. (2000) Moneda y sistemas monetarios en Castilla y León. Barcelona.

RUEDA SABATER, M. (1991) Las primeras acuñaciones de Castilla y León. Valladolid: Junta de Castilla y León.

- (1992) "Hallazgos de moneda medieval castellana y leonesa", Numisma, 230.

- (1996) "Monedas y circulación monetaria en el Reino de León", Historia de León a través de la Arqueología, León.

SÁNCHEZ-ALBORNOZ, C. (1928) "La primitiva organización monetaria en Castilla y León", AHDE.

- (1965) Una ciudad en la España cristiana de hace 1000 años. Barcelona: Rialp.

SPPUFFORD, P. (2000) "Monetary Practice and Monetary Theory in Europe (12th-15th. Centuries)", Moneda y monedas en la Europa occidental (Siglos XII-XV), XXVI Semana de Estudios medievales de Estella, Pamplona.

TODESCA, J. (1988) "Money of Account and Circulating Coins in Castile-Leon c. 1084-1300", Problems of Medieval Coinage in the Iberian Area, III, Santarem.

Torres LÁZARO, J. (1996) "El ordenamiento de Cuenca", Numisma, 238.

- (2000) "Monederos de piedra", Crónica Numismática, Barcelona,111. 
VALDEón BARUQUe, J. (1966) "Las reformas monetarias de Enrique II de Castilla", Homenaje al profesor Emilio Alarcos, Valladolid.

VV.AA. (2000) Moneda y monedas en la Europa occidental (Siglos XII-XV), XXVI Semana de Estudios medievales de Estella, Pamplona.

- (2000): Dinero, moneda y crédito en la monarquía hispánica. Madrid: M. Pons.

- (1984-1988) Problems of Medieval Coinage in The Iberian Area, Lisboa 1984, Avilés 1986, Santarem 1988. 